\title{
COOPERAÇÃO INSTITUCIONAL COMO ESTRATÉGIA INOVATIVA: O CASO DO APL DE CONFECÇÕES EM CAMPINA GRANDE (PB)*
}

\author{
Paulo Fernando de M. B. Cavalcanti Filho ${ }^{* *}$
}

\section{Lúcia Maria Góes Moutinho}

\begin{abstract}
RESUMO Neste trabalho desenvolve-se o estudo do Arranjo Produtivo Local (APL) de Confecções em Campina Grande, na Paraíba, a partir da abordagem de desenvolvimento industrial e da economia da inovação e do conhecimento, focalizando as ações de aprendizado, capacitação e relações de cooperação dos vários atores do APL. Conclui-se que o desempenho inovativo é significativamente melhorado pela utilização de uma estratégia cooperativa de desenvolvimento tecnológico, como exemplificado pela análise do consórcio formado em torno do algodão naturalmente colorido.
\end{abstract}

Palavras-chave: cooperação institucional; APL de confecções; estratégias inovativas

Código JEL: L60, L53 e M20 ou O1 e O3

\section{INSTITUTIONAL COOPERATION AS INNOVATIVE STRATEGY:}

THE LPA EVENT IN SEWING AT CAMPINA GRANDE (PB)

ABSTRACT In this research is developed the study of Local Productive Arrange (LPA) of Sewing at Campina Grande, in Paraiba. Is followed a line of investigation

\footnotetext{
* Artigo recebido em 3 de outubro de 2005 e aprovado em 7 de agosto de 2007.

** Professor e pesquisador do Núcleo de Estudos em Tecnologia e Empresa do Departamento de Economia da UFPB, e-mail: ecavalcantifilho@hotmail.com

*** Professora de Economia no DLCH/UFRPE, pesquisadora associada da RedeSist IE/UFRJ e pesquisadora do NETE - Núcleo de Estudos em Tecnologia e Empresa da UFPB/UFRPE/FUNDAJ, e-mail: luma121@hotmail.com
} 
of industrial development and innovative economy and knowledge, focusing in learning actions, upgrading and cooperation relation between all LPA's participants. Is concluded that innovative performance is better improved by using an innovative strategy of technological development, as explained by an analyses of alliance created around the natural colored cotton.

Key words: institutional cooperation; LPA of sewing; innovative strategies 


\section{INTRODUÇÃO}

A dinâmica institucional no processo de desenvolvimento econômico vem sendo crescentemente destacada na literatura especializada, a partir de diferentes abordagens. A ênfase nos aspectos sistêmicos e evolutivos de um determinado espaço constitui o core da idéia de Sistemas Nacionais de Inovação (Freeman, 1987; Lundvall, 1992; Nelson, 1993; Edquist, 1997). As especificidades locais, no interior dos territórios nacionais, de acordo com essa literatura, fundamentam possibilidades de cooperação e governança que favorecem as condições de competitividade através da inovação.

Essa percepção da relevância do "local", no interior do atual paradigma técnico-econômico dominante em esfera global, possibilitou o desenvolvimento de uma nova abordagem conceitual, teórica e instrumental, que enfatiza o fenômeno do aprendizado inovativo a partir de relações enraizadas territorialmente. Esta abordagem busca compreender e explicar como a atividade econômica e inovativa, desenvolvida em subespaços nacionais, mesmo em dimensões territoriais extremamente reduzidas (inferiores aos limites municipais), encontram formas e mecanismos, específicos ao local, que permitem sua inserção nos diversos processos (produtivos, competitivos, tecnológicos, financeiros, etc.) que se desenvolvem em dimensão nacional e mundial (Lastres, Cassiolato e Arroio, 2005).

Nas condições do atual paradigma, o conhecimento tornou-se o fator básico de desenvolvimento, e o ritmo, direção e formas que este pode assumir são condicionados, favorecidos ou restritos pelo conjunto de instituições presentes e atuantes no território, seja este local, nacional ou global (Johnson \& Lundvall, 2005).

Ao possibilitar a proximidade não apenas geográfica, mas cultural e institucional, entre indivíduos, firmas e organizações, a dimensão institucional local cria e fortalece uma rede de proteção contra as incertezas inescapáveis envolvidas nos processos de aprendizado inovativo. Instituições armazenam conhecimentos, tanto em formas materiais quanto tacitamente, e os procedimentos formais e informais desenvolvidos historicamente para o exercício de suas funções podem tanto beneficiar quanto restringir a eficácia de suas ações, a depender de sua adequação ao contexto e momento. 
A maior/menor intensidade das interações entre essas organizações e as firmas, à medida que esses agentes se encontram estabelecidos e concentrados localmente, sofre um processo de retroalimentação, possibilitada e potencializada pelo compartilhamento de normas, convenções, valores, expectativas e rotinas que nascem da experiência comum.

Com maior ou menor ênfase, a depender da sua filiação teórica, as diversas abordagens que fundamentam os estudos de aglomerações espaciais de empresas usualmente destacam o papel de fatores sociais, culturais e políticos. Esses fatores afetam a formação e a evolução de distritos industriais, clusters e outras formas de concentração de atividades produtivas em um mesmo território.

O "modo de funcionamento" dessas aglomerações pode ser compreendido observando-se a diversidade e a complementaridade dos agentes envolvidos, sejam empresariais ou não empresariais, seja por mecanismos de mercado ou de outras instituições, na construção e eficácia dos processos de produção e inovação. ${ }^{1}$

As estruturas e o modo de funcionamento desses espaços de aglomeração empresarial e institucional configuram um objeto teórico cuja observação e análise são favorecidas pela noção de sistemas e arranjos produtivos e inovativos locais (Aspils), privilegiando um recorte analítico-espacial que procura captar as especificidades que se apresentam nesse nível (Lastres, Cassiolato \& Arroio, 2005). A proximidade entre os agentes locais, pelo compartilhamento de valores comuns e pela construção de confiança mútua, estimula comportamentos cooperativos, necessários aos processos de aprendizagem, por sua natureza interativos e sociais (Lundvall, 1992).

A abordagem de Aspils, ${ }^{2}$ em especial, destaca:

(i) A importância da cooperação não apenas entre empresas, mas inclusive destas com outros atores locais, tais como centros de pesquisa, as várias esferas de governo, instituições de apoio e de fomento.

(ii) Que a cooperação é facilitada pela confiança mútua, valores comuns e enraizamento histórico no mesmo território.

(iii) Que a inovatividade, como processo coletivo e sistêmico, requer a contribuição de distintos atores e é fortalecida pela constituição de um sistema de inovação local. 
Nessa direção o presente artigo desenvolve o estudo do Arranjo Produtivo Local de Confecções de Campina Grande na Paraíba a partir da abordagem de desenvolvimento industrial, da economia da inovação e do conhecimento, focalizando as ações de aprendizado, capacitação e relações de cooperação dos vários atores do APL: as empresas produtoras, fornecedoras de bens e de serviços, suas diversas formas de representações e instituições de apoio, quer governamentais, quer privadas, com vistas a sugestões de políticas voltadas para o dinamismo e a sustentabilidade, da atividade bem como para a internalização dos resultantes benefícios sociais.

O trabalho apresenta evidências empíricas oriundas de um estudo inédito sobre a aglomeração produtiva ${ }^{3}$ e tem naturezas quantitativa e qualitativa, sem desconsiderar o aspecto histórico. Adicionalmente, quanto aos fins, a pesquisa pode ainda ser classificada como exploratória e explicativa. A natureza de algumas informações coletadas a partir de fontes indiretas e a forma como foram tratadas e interpretadas atribuem, adicionalmente, a esta investigação um caráter bibliográfico e documental. Desse modo, encontra-se organizada em sete partes, além desta introdução: (1) O APL de confecções de Campina Grande: descontinuidades de políticas e programas de suporte à competitividade; (2) O perfil empresarial do APL confeccionista de Campina Grande; (3) O ambiente e o território; (4) O processo inovativo no APL; (5) Cooperação como estratégia inovativa no APL; (6) Cooperação e estratégia inovativa: o consórcio do algodão colorido; e (7) Conclusões.

\section{O APL DE CONFECÇõEs DE CAMPINA GRANDE: DESCONTINUIDADES DE POLÍtICAS E PROGRAMAS DE SUPORTE À COMPETITIVIDADE}

A ocorrência de descontinuidades em políticas e programas de suporte à competitividade e a existência de rivalidades e conflitos entre grupos sociais e políticos comprometem o dinamismo e sustentabilidade de Aspils no longo prazo. Ausente ou perdida a confiança mútua, os esforços para estimular a prática cooperativa tendem a se mostrar infrutíferos, pois encontram um solo estéril para a ação coletiva, uma vez que não se identificam interesses comuns.

Caracterizado por disputas políticas acirradas, o Estado da Paraíba tem vivenciado um duplo processo de "guerra fiscal", em escala regional e, idios- 
sincraticamente, em escala estadual, com os mesmos resultados práticos: ganhos particulares e perdas coletivas.

Em um plano regional, o Estado foi pioneiro no estabelecimento de uma agressiva política de incentivos, de naturezas material, fiscal e financeira, com o intuito de atrair empreendimentos industriais de outros Estados da região Nordeste e de outras regiões do País. Seu pioneirismo no estabelecimento dessa chamada "guerra fiscal" possibilitou vantagens, pela ausência de grande número de Estados competindo pelos investimentos. ${ }^{4}$

No plano estadual, observa-se que os investimentos realizados, sejam aqueles atraídos pela política de incentivos, sejam os projetos "endógenos" de estímulos a setores industriais já estabelecidos, têm sua localização definida a partir de critérios marcadamente políticos, embora outras variáveis socioeconômicas também preservem sua influência.

Nesse sentido, se nos anos 1980 o Município de Campina Grande beneficiou-se dos incentivos estaduais/federais para atração e implantação de uma grande unidade produtora de calçados (Alpargatas), e no início da década de 1990 atraiu o maior grupo têxtil do Brasil (Embratex-Coteminas), no final desta mesma década a capital do Estado (João Pessoa) e seus municípios mais próximos (Bayeux, Santa Rita e Cabedelo) foram favorecidos com a instalação de unidades industriais produtoras de calçados (Penalty e Samello) incentivadas pelo Fundo de Apoio à Industrialização da Paraíba - FAIN.

A atividade confeccionista na Paraíba não deixou de ser diretamente afetada por essa característica local, e ao longo da sua história as oscilações da atividade seguem uma forma peculiar do chamado "ciclo político", pois têm dependido e se desenvolvido em torno da disputa entre os Municípios de João Pessoa e Campina Grande pelo poder local, de tal forma que as atividades econômicas, sediadas nos dois municípios, são beneficiadas em função do grau de sintonia entre os poderes estadual e municipal. A evolução do APL de confecções em Campina Grande ilustra esse fenômeno, uma vez que se ajusta com muita propriedade à dinâmica político-econômica paraibana.

O Arranjo Produtivo de Confecções de Campina Grande originou-se de uma Associação de Confeccionistas, fundada em 1981, e, à época, formada por 11 costureiras, "senhoras de classe média", que pretendiam evoluir de um trabalho doméstico para uma atividade de natureza empresarial. Du- 
rante um ano, o Sebrae (PB) financiou o treinamento das integrantes da Associação nas instalações do Senai (localizado em Natal (RN)), e, a partir da iniciativa das empresárias mais engajadas do grupo, formou-se, na Federação da Indústria da Paraíba - FIEP, o Sindicato da Indústria do Vestuário da Paraíba - Sindvest.

Em 1984, iniciou-se a construção do Centro Comercial de Ação Luiza Motta, o qual permaneceu inconcluso até 1990, prédio empresarial com a função de disponibilizar espaço comum para comercialização das empresas produtoras de confecções e de calçados em Campina Grande. Na perspectiva dos próprios agentes do APL, o impacto da obra representou um "divisor de águas" na história de Campina Grande, pois das 11 empresas iniciantes, em 1981, esse número chegou a 142 empresas de confecções em 1992.

Enquanto o Centro Comercial preservou sua natureza inicial de especialização em lojas de fábrica de confecções e calçados, a administração esteve sob o controle do Sebrae (PB) (desde junho de 1991). Entretanto, após sua transformação em shopping center em 1997, com diversidade de produtos (além de vestuário) e sem vínculo comércio-indústria, o Sebrae ( $\mathrm{PB}$ ) percebeu que não era sua função administrar esse tipo de estabelecimento comercial. Assim, em março de 1999, o Sebrae (PB) transferiu a administração para a Associação de Lojistas do Shopping Luiza Motta. Ao mesmo tempo, foi construído o shopping Sebrae de João Pessoa, voltado prioritariamente para a comercialização de confecções, cuja administração foi assumida pela antiga diretoria de Campina Grande.

No APL de confecções de Campina Grande há um significativo e diversificado conjunto de agentes empresariais e não empresariais. Entretanto, suas ações iniciais mostravam-se desarticuladas e focalizadas, além de sensíveis à alternância de poder político no Estado da Paraíba. O quadro 1 expõe os agentes e suas formas de interação no APL.

O Sebrae e o governo estadual, através da Companhia de Desenvolvimento da Paraíba - Cinep, são os principais agentes que atuam junto às empresas de confecções da Paraíba. Seja pelo poder de mobilização de recursos, seja pela periodicidade das políticas e programas, o Sebrae (APL) e o governo estadual possuem capacidade para promover atividades de largo alcance e impacto no APL de confecções de Campina Grande. 
Além de vários programas de treinamento e apoio, a exemplo do Patme (Programa de Apoio Tecnológico às Micro e Pequenas Empresas), que financia e capacita micro e pequenas empresas (MPEs) na área de modernização tecnológica e desenvolvimento de inovações, o Sebrae atua localmente, promovendo os produtores de confecções através do Projeto de Desenvolvimento da Cadeia Produtiva Têxtil-Confecções da Paraíba. O governo estadual, por seu lado, apesar da pequena arrecadação tributária, possui recursos materiais, fiscais e financeiros significativos, relativamente ao porte do APL campinense, principalmente através da Cinep, promovendo obras (como reforma de instalações físicas) e financiando treinamento de recursos humanos.

Quadro 1: Atores do APL e formas de interação

\begin{tabular}{|c|c|c|}
\hline Atores do arranjo & Identificação & Formas de interação $^{6}$ \\
\hline Clientes & $\begin{array}{l}\text { Consumidores, Shopping } \\
\text { Luiza Motta, Shopping } \\
\text { Sebrae-João Pessoa, } \\
\text { governos municipal } \\
\text { e estadual }\end{array}$ & $\begin{array}{l}\text { Troca de informações, perfil de demanda em termos } \\
\text { dos prazos de entrega, sazonalidade, preços, moda, } \\
\text { local de comercialização etc. }\end{array}$ \\
\hline Fornecedores & $\begin{array}{l}\text { Empresas de fiação, } \\
\text { aviamentos e tecelagem }\end{array}$ & $\begin{array}{l}\text { Características técnicas dos insumos e componentes, } \\
\text { troca de informações técnicas, contratos e parcerias } \\
\text { etc. }\end{array}$ \\
\hline $\begin{array}{l}\text { Sindicatos, } \\
\text { Associações } \\
\text { e Federações }\end{array}$ & $\begin{array}{l}\text { FIEP, Sindicato dos } \\
\text { Trabalhadores, Associação } \\
\text { das MPEs de Campina } \\
\text { Grande, Sindicato da } \\
\text { Indústria do Vestuário } \\
\text { no Estado da Paraíba, } \\
\text { Instituto Casaco de Couro }\end{array}$ & $\begin{array}{l}\text { Difusão de informações tecnológicas e mercadológicas, } \\
\text { apoio legal e institucional, promoção de cursos e } \\
\text { eventos técnicos e comerciais, feiras, articulação } \\
\text { política e planejamento estratégico etc. }\end{array}$ \\
\hline $\begin{array}{l}\text { Centros de } \\
\text { Pesquisa } \\
\text { Tecnológica }\end{array}$ & $\begin{array}{l}\text { Centro Nacional de Pesquisa } \\
\text { do Algodão/Embrapa, } \\
\text { Laboratório de Confecções } \\
\text { e Vestuário (Labvest) do } \\
\text { Centro de Tecnologia do } \\
\text { Couro e do Calçado }\end{array}$ & $\begin{array}{l}\text { Pesquisa e desenvolvimento de tecnologia para o } \\
\text { algodão colorido/Projeto Cultivar BRS 200; } \\
\text { pesquisa referente a design, modelagem, produção } \\
\text { e qualidade, concentrando-se em produtos do } \\
\text { algodão colorido, englobando roupas, acessórios e } \\
\text { decoração }\end{array}$ \\
\hline Órgãos Públicos & $\begin{array}{l}\text { Cinep, Sebrae, Senai, } \\
\text { Sine, Sesi, IEL, Secretaria } \\
\text { Municipal da Indústria } \\
\text { e Comércio }\end{array}$ & $\begin{array}{l}\text { Financiamento de cursos para treinamento } \\
\text { empresarial e de mão-de-obra, apoio ao } \\
\text { desenvolvimento de capacitação tecnológica, } \\
\text { projetos inovativos etc. }\end{array}$ \\
\hline Atores Políticos & $\begin{array}{l}\text { Governos estadual e } \\
\text { municipal, agrupamentos } \\
\text { políticos locais }\end{array}$ & $\begin{array}{l}\text { Implementação de políticas públicas, articulação } \\
\text { interinstitucional entre esferas de poder, mobilização } \\
\text { de recursos humanos, econômicos e financeiros }\end{array}$ \\
\hline Universidades & UFPB, UFCG, UEPB & $\begin{array}{l}\text { Formação de recursos humanos qualificados, } \\
\text { pesquisas e atividades de extensão }\end{array}$ \\
\hline Agentes Financeiros & $\begin{array}{l}\text { Banco do Brasil, Banco } \\
\text { do Nordeste, Ceape/PB }\end{array}$ & $\begin{array}{l}\text { Financiamento de capital de giro, empréstimos para } \\
\text { investimentos em capital físico, microcrédito }\end{array}$ \\
\hline
\end{tabular}

Fonte: Elaboração própria. 
Além desses atores principais, outras instituições estão presentes no APL. São várias as agências de financiamento e promoção das MPEs atuantes na Paraíba. Entretanto, não há linhas de crédito ou programas específicos para o arranjo de confecções. No Município de Campina Grande, estão presentes o Banco do Nordeste do Brasil - BNB e o Banco do Brasil - BB, ambos possuindo programas e linhas de crédito para micro e pequenos empresários. ${ }^{5}$

Outro agente financeiro relevante no APL é o Centro de Apoio aos Pequenos Empreendimentos - Ceape, uma Organização da Sociedade Civil de Interesse Público - Oscip, ${ }^{7}$ com atuação em todo o Estado, dedicado ao desenvolvimento socioeconômico das MPEs, entre outros empreendimentos, dirigido por pessoas de baixa renda. Aproximadamente entre $85 \%$ e $87 \%$ dos créditos são para o comércio, $10 \%$ para a produção e de $3 \%$ a $5 \%$ para os serviços. A maior parte do crédito destina-se ao comércio informal de confecções.

\section{O PERFIL EMPRESARIAL DO APL CONFECCIONISTA DE CAMPINA GRANDE}

A distribuição espacial das MPEs de confecções, na Paraíba, está concentrada em quatro Arranjos Produtivos Locais - APLs, situados nos municípios de Guarabira, Alcantil, João Pessoa e Campina Grande.

Analisando os dados da Relação Anual de Informações Sociais do Ministério do Trabalho - Rais em 2001, a indústria de confecções, na Paraíba, era formada por 247 empresas formais, gerando um total de 3.196 empregos. Percebe-se que os Municípios de João Pessoa e Campina Grande possuíam cerca de 39\% destas (96 e 98 empresas, respectivamente); entretanto, em termos de emprego, João Pessoa concentrava cerca de 40\% dos trabalhadores do setor (1.296 empregos), enquanto Campina Grande caía à metade em sua participação, ou seja, cerca de $20 \%$ do emprego total (647). Ambos os municípios apresentavam aglomerações de MPEs, respectivamente, com 13 e sete empregados por empresa, em média.

Tem-se duas bases de dados para investigar a evolução do número de estabelecimentos confeccionistas em Campina Grande. De acordo com os dados do cadastro da FIEP, havia 142 empresas formais no ano de $1992^{8}$, reduzindo-se este número para apenas 98 empresas no ano de 1997 (de um 
Gráfico 1: Evolução da participação percentual de empresas de confecções dos Municípios de João Pessoa e Campina Grande entre 1992 e 2001

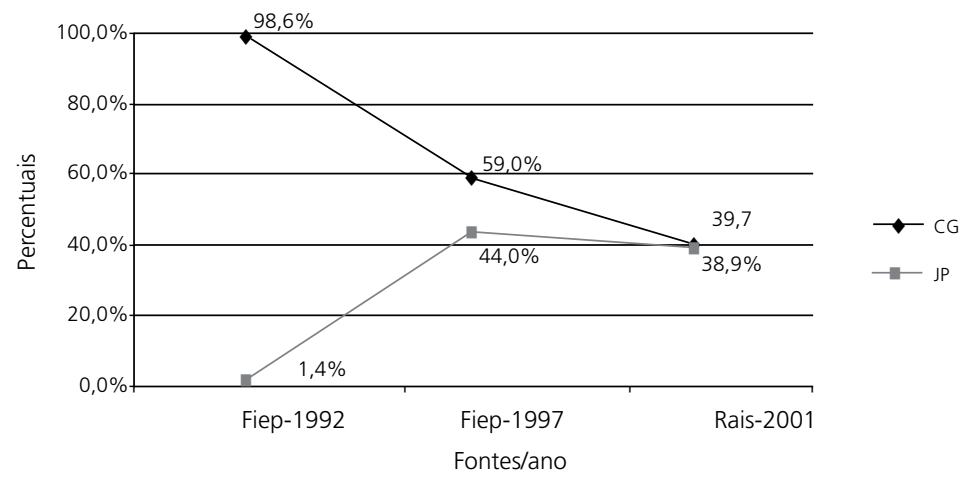

Fonte: Cavalcanti Filho \& Moutinho, 2004.

total de 166 empresas no estado 9 ). Nos dados da RAIS para 2001 constavam 98 empresas formais (mesmo número da FIEP para o ano de 1997).

Em relação a João Pessoa, verificou-se que, no cadastro da FIEP, o número de estabelecimentos do setor de confecções alcançou a marca de 73 em 1997, enquanto nos dados da RAIS, para 2001, registrava-se a existência de 96 empresas na capital paraibana (gráfico 1).

Para a pesquisa apresentada neste artigo e desenvolvida ao longo do segundo semestre de 2003, foi selecionada uma amostra de 21 empresas confeccionistas de Campina Grande, composta da seguinte forma:

(a) Sete pequenas empresas, representando $33 \%$ da amostra, sendo $28,5 \%$ destas selecionadas a partir da listagem do Sindvest e $71,5 \%$ da listagem da Fiep;

(b) 14 microempresas, representando $67 \%$ da amostra, sendo $35,7 \%$ destas retiradas da listagem do Sindvest e 64,3\% da listagem da FIEP.

De acordo com os resultados da amostra selecionada para a pesquisa, em um total de 21 MPEs entrevistadas, verificaram-se 346 empregos formais, com 16 empregados, em média, por empresa. Esses resultados parecem indicar que a "crise do segundo mandato de Fernando Henrique Cardoso - FHC", relatada nas entrevistas com os empresários, foi responsável pelo fechamen- 
to de várias empresas de porte muito pequeno, tendo sobrevivido aquelas de maior porte, em termos do número de empregados. Não se percebe a existência de uma cadeia produtiva completa e integrada capaz de caracterizar economicamente o município, à semelhança do APL de calçados.

Verifica-se que o APL é formado por empresas com idade média de 12 anos, o que configura um arranjo com razoável experiência acumulada, tendo já usufruído de economias de aprendizado na produção e na comercialização.

Percebe-se que, das empresas que surgiram após o período recessivo 1981-1983, sete estão presentes na amostra do APL, todas fundadas no período em que a atividade econômica havia se recuperado, entre 1985 e 1989. As demais empresas da amostra (13) foram fundadas no período de 1992 a 1996, isto é, apenas após a economia recuperar-se da recessão de 1990-1991. Destaque-se que, nos dois anos de profunda recessão, 1990-1991, não há empresas fundadas entre aquelas que compõem a amostra, mas, de acordo com o cadastro da Fiep para 1992, verifica-se que 52,11\% das empresas registradas à época iniciaram suas atividades exatamente nesses anos recessivos. Isso contrasta com o fato de 23,2 e 21,8\% das empresas registradas no cadastro de 1992 terem sido fundadas, respectivamente, no período pré1985 e no intervalo 1985-1989, e representarem 4,75 e 33,3\% da amostra. Dessa forma, denominam-se neste capítulo "1a geração" e "2a geração" os grupos de empresas cujas datas de fundação tenham ocorrido antes ou após, respectivamente, o período recessivo 1990-1991.

Entre as empresas da "2a geração" (1992-1996), há uma pequena predominância de controle por um único proprietário (54\%), enquanto entre as da "1a geração" (1981-1989) havia forte predominância do controle por dois ou três sócios (63\%). Pode-se afirmar que as empresas da "1a geração" teriam uma tendência a uma maior "abertura" de seu capital. ${ }^{10}$ A maior restrição de crédito bancário, a existência de valores e da cultura associativa e/ou a necessidade de maiores requerimentos de capital inicial podem ser possíveis explicações para a maior incidência na "1a geração" de capital societário identificado.

Parece haver uma relação entre a sobrevivência das empresas de confecções de Campina Grande e o nível de atividade econômica ao longo da existência do APL, dada a concentração de empresas fundadas entre as recessões 
1981-1983 e 1990-1991 e após esta última e a estagnação pós-reeleição do presidente Fernando Henrique Cardoso. Uma explicação para essa relação entre expansão inicial e permanência no mercado poderia decorrer da presença de significativas cumulatividades no aprendizado tecnológico, gerencial e de mercado, que permitiria ganhos iniciais do rápido processo de acumulação de capital físico e de habilidades e conhecimento tecnológico. Dessa forma, essas empresas acumulariam vantagens em relação àquelas que enfrentaram um período recessivo logo nos primeiros meses de sua existência e que permitiram maior competitividade para sobreviver aos períodos recessivos posteriores e à concorrência de novas rivais. ${ }^{11}$

\section{O AMBIENTE E O TERRITÓRIO}

O cenário macroeconômico adverso enfrentado pela economia brasileira, nesse período, possivelmente é um dos fatores explicativos desse mau desempenho recente, mas não o principal, pois se observou expansão significativa no setor de confecções no vizinho Estado de Pernambuco. ${ }^{12}$ Apesar dessa perda no número de estabelecimentos, a importância do APL de Campina Grande, no contexto da economia paraibana, preserva sua relevância por pelo menos cinco motivos, os quais justificaram sua seleção como área da pesquisa:

(a) Sua significativa retração, nos últimos anos, provocou impactos negativos na economia local, sendo necessário conhecer as possíveis causas explicativas desse fenômeno para fundamentar a orientação de políticas públicas.

(b) Co-existência espacial de outro APL (couro e calçados), permitindo analisar efeitos sinérgicos na articulação dos agentes de ambos os APLs, bem como verificar a validade de hipóteses sobre vantagens locais, efeitos de políticas e estratégias empresariais.

(c) Proximidade espacial com os APLs de confecções instalados em municípios pernambucanos, bem como do Município paraibano de $\mathrm{Al}$ cantil, caracterizando-se uma macrorregião interestadual especializada na produção de confecções.

(d) Densidade institucional local voltada para confecções visivelmente maior do que a observada nos demais municípios onde se desenvolve a atividade na Paraíba e em Pernambuco. 
(e) O fato de esse município sediar o consórcio de MPEs, que vem desenvolvendo a estratégia competitiva mais ousada em termos tecnológicos, comerciais e institucionais: a produção e exportação de confecções à base de algodão naturalmente colorido.

Considerando-se os segmentos de mercado (renda média, no espaço regional) em que sua produção enfrenta a concorrência (de São Paulo, principalmente), sua competitividade baseia-se no baixo preço dos produtos, uma vez que as vendas de suas rivais são impulsionadas pela capacidade em design e pelo acesso à informação sobre as tendências da moda, bem como pela força das marcas da região Sudeste.

O aproveitamento de uma mão-de-obra habilidosa e a engenhosidade empresarial (característica da cultura campinense), juntamente com o aprendizado imitativo do tipo learning-by-watching, têm permitido acompanhar, após o lançamento das coleções nacionais e internacionais, as tendências para o design em confecções, permitindo que pequenas empresas campinenses se especializem na fabricação de confecções femininas e infanto-juvenis. Em termos da classificação CNAE, 66,6\% da amostra têm como segmento de atividade principal a confecção de "outras peças do vestuário", $14,5 \%$ fabricam “outras peças interiores do vestuário”, o mesmo percentual dedica-se a "peças do vestuário produzidas em malha" e apenas 5\% dedicam-se a "fardamentos". Em geral são vendidos em lojas próprias locais e, com raras exceções, em lojas de shopping centers e redes de supermercados da região.

As empresas, em geral, não reconhecem vantagens relevantes no ambiente local, governança e estrutura, no entanto, podem ser destacados alguns pontos importantes a esse respeito. A proximidade com clientes e consumidores e a infra-estrutura foram tidas pelas MPEs como as vantagens mais importantes (66\% de média/alta importância), enquanto a proximidade de fornecedores de insumos e produtores de equipamentos é praticamente descartada como "vantagem" para mais de 70\% das empresas.

As microempresas não vêem vantagem em serviços técnicos especializados, um comportamento diferenciado em relação às pequenas, que encontram essa vantagem no APL. Essa diferença pode decorrer de as empresas possuírem maior informação sobre esses serviços, ou que estes estejam disponíveis mais diretamente às pequenas empresas. 
As microempresas, ao contrário das pequenas, adquirem bens e serviços principalmente no APL, seja pela falta de capital, de segurança, ou de rede de informações com outros fornecedores. Tratando-se destas últimas, a venda de produtos e a aquisição de serviços são os itens mais destacados e mais importantes em relação às microempresas.

O piso salarial dos trabalhadores, à época, era 20\% inferior ao fixado no Estado de Pernambuco (respectivamente R\$253,00 e R \$317,09), sendo uma vantagem de média ou de alta importância para $47 \%$ das empresas da amostra; entretanto o mesmo percentual afirma ser de "nula" importância esse menor custo salarial.

O conhecimento prático quanto à produção, criatividade, disciplina, flexibilidade e capacidade de aprender novas técnicas são os predicados da mão-de-obra local mais destacados e os pontos mais comuns entre as MPEs. Para as microempresas, a escolaridade formal básica — Ensino Fundamental e Médio - é suficiente, enquanto $57 \%$ das pequenas apontam como muito importante uma mão-de-obra qualificada, de nível técnico e/ou superior.

Mais de 50\% das empresas não reconhecem vantagens nos programas de apoio ao APL. Sindicatos e associações são mais ativos e valorizados pelas pequenas empresas, mostrando um certo grau de cooperação e integração entre elas, enquanto as microempresas avaliam negativamente todas as ações dessas organizações.

\section{O PROCESSO INOVATIVO NO APL}

A inovatividade, cooperação e aprendizado das empresas do APL estão fortemente relacionados ao suporte institucional disponível que se caracteriza por sua densidade e atuação como facilitador do desenvolvimento das empresas de confecções de Campina Grande. Nesse caso, uma análise do processo de inovação do APL não poderia prescindir da identificação e do conhecimento das relações de parceria entre atores institucionais do APL, bem com das articulações entre eles e os consórcios de empresas.

Analisando a inovatividade, cooperação e aprendizado das empresas no período 2000-2002, verificou-se que para quase todas as atividades listadas (no questionário da pesquisa) ${ }^{13}$ havia ao menos uma empresa da amostra que afirmava tê-las realizado, de forma ocasional ou rotineira. Ao mesmo 
tempo, em média, para cada tipo de atividade inovativa, cerca de $70,8 \%$ das empresas afirmavam não tê-la realizado, enquanto $14,8 \%$ das empresas o fizeram de forma ocasional e apenas 14,2\% de forma rotineira.

Esse resultado, de um lado, indica a freqüência elevada de atividades inovativas por parte das empresas do APL e o espaço para troca de informações, conhecimentos e habilidades tecnológicas, e, de outro, revela a reduzida densidade e amplitude dessas atividades, uma vez que a dispersão de áreas de busca inovativa dificulta a possibilidade de haver cooperação tecnológica entre as empresas, pois é preciso um mínimo esforço interno de capacitação tecnológica para que seja possível o "diálogo" na parceria inovativa.

As atividades inovativas mais freqüentes foram "P\&D interno à empresa" e "Aquisição de outras tecnologias", com percentuais de 52,4 e 47,7\%, respectivamente, para a soma das respostas "ocasional" e "rotineira". Uma vez que se trata de MPEs, o elevado percentual para a atividade de "P\&D interno" deve ser relativizado, ao menos em dois aspectos:

- Em primeiro lugar, o principal sócio-fundador possuía nível superior (completo ou incompleto) em 83,3\% das empresas que afirmaram ter realizado "P\&D", e os demais $16,6 \%$ possuíam o $2^{\circ}$ grau completo. Esse dado permite inferir que os entrevistados tinham conhecimento da importância dessa atividade tecnológica para o sucesso empresarial no mundo moderno e poderiam realizar atividades de busca tecnológica de forma "artesanal", mas consciente e sistematicamente.

- Em termos de porte, das empresas que realizaram atividade de P\&D, $41,6 \%$ eram pequenas e $58,3 \%$ eram microempresas. ${ }^{14}$ Entretanto, apenas $28,6 \%$ das empresas, entre elas apenas uma microempresa, avaliaram a atividade de P\&D como tendo "alta importância"; todas as demais afirmaram ser "nula" sua importância.

Sendo a atividade de P\&D caracterizada por elevada incerteza quanto aos seus resultados, gastos significativos (em termos absolutos e relativos) e exigência prévia de capacitação tecnológica interna, uma empresa não empreenderia tal atividade se a considerasse de "nula importância". Portanto, o grau de importância atribuído à $\mathrm{P} \& \mathrm{D}$ parece ser um indicador mais fiel, embora indireto, da ocorrência dessa atividade tecnológica no APL, relativamente à resposta direta dos empresários. 
Pode-se concluir, contudo, que parece haver uma forte relação entre o grau superior de escolaridade e a realização de atividades de $\mathrm{P} \& \mathrm{D}$, bem como entre o maior porte empresarial e o alto grau de importância atribuído aos resultados dessa atividade.

Em relação aos diversos tipos de inovação realizados pelas empresas do APL, podem ser destacados alguns resultados: verifica-se que $66 \%$ das empresas afirmaram ter introduzido um produto novo na sua empresa, enquanto apenas $9,5 \%$ afirmaram que seu novo produto era também uma inovação no mercado nacional. Em termos de "novos desenhos" para os produtos já existentes, apenas 19\% da amostra afirmaram não ter introduzido esse tipo de inovação. Apesar de algumas empresas possuírem experiência anterior com exportação, ${ }^{15}$ nenhuma delas afirmou ter introduzido uma inovação de produto no mercado internacional para o período 20002002.

As empresas que adotaram inovações de processo, em seu setor, apresentaram um percentual que é duas vezes maior do que o das empresas que introduziram inovações de produto em seu mercado (19 e 9,5\%, respectivamente). Por outro lado, o percentual daquelas empresas que introduziram inovações de processo interno à empresa foi inferior ao das que introduziram inovações de produto na empresa, dos tipos de inovações que já eram conhecidas em seu mercado (52\% e 66,6\%, respectivamente).

Esses resultados parecem indicar que é mais fácil introduzir inovações de processos (relativamente a produtos) no setor, bem como introduzir imitações de produto no mercado. É razoável supor, contudo, que o entendimento do que significa "inovações no setor" represente mais precisamente os competidores diretamente atuantes nos mercados-alvo dos entrevistados, e não necessariamente o "estado da arte" das tecnologias de processo e produto, em escala internacional.

Analisando-se por gênero, verificou-se um desempenho diferenciado entre mulheres e homens, cuja explicação poderia ser encontrada na escolaridade do principal sócio-fundador, pois entre as sócias há uma predominância daquelas com escolaridade superior (75\%), em comparação com sócios $(55,5 \%)$. As empresas administradas por mulheres (EAM) se mostram mais inovativas na área do produto que na do processo, comparando com as empresas administradas por homens (EAH), pois, enquanto $50 \%$ das 
EAH inovaram, entre as EAM, $81,8 \%$ responderam que introduziram um novo produto para as suas empresas, mas já existente no mercado, crescendo esses percentuais para 70 e 90,9\%, respectivamente, para inovações no desenho dos produtos.

$\mathrm{Na}$ área de processo, entretanto, não se observa diferenciação estatisticamente significativa no desempenho entre EAH e EAM, porque $50 \%$ das primeiras permanecem inovativas em processo para sua própria empresa, enquanto o percentual das EAM cai para 59,09\%. O mesmo se observa nos dados sobre inovações de processo no setor de atuação.

Suas estratégias de inovação, de fato, caracterizam-se por imitação do mercado nacional, pois apenas 10 e 9,1\% das empresas EAH e EAM, respectivamente, introduziram inovações no mercado nacional. Dada a exclusividade das EAM à “modinha” feminina no segmento de maior apelo inovativo, em que $80 \%$ das empresas desse segmento afirmaram ter introduzido inovações de produto (confirmando a suposição), e como o acompanhamento da moda, através de revistas, televisão, vitrines etc., permanece como "hábito" feminino, parece configurar-se uma explicação plausível para a evidência da predominância feminina na inovação de produto por imitação do mercado nacional. Essas inovações de produto e de desenho são facilitadas pelo fato de as mulheres, em geral, serem responsáveis pela gerência de produção, mesmo quando o principal sócio é o homem.

As empresas do APL têm um fraco desempenho inovativo na área de gestão: apenas 19\% introduziram inovações gerenciais, enquanto quase $48 \%$ o fizeram na estrutura organizacional. Igualmente, nas áreas vinculadas à seção de vendas, incluindo embalagem, marketing e comercialização, as empresas também apresentaram um desempenho fraco, em especial nas duas últimas áreas.

Por tamanho, verifica-se que as pequenas empresas são mais inovativas do que as microempresas, com 85,7 e 57\% introduzindo inovações de produto para a própria empresa, respectivamente. Em relação à inovação de processo para a própria empresa, $71,4 \%$ das pequenas e $42,8 \%$ das microempresas o fizeram. No âmbito nacional, nenhuma microempresa introduziu inovações de produto no setor de atuação; contudo $28,6 \%$ das pequenas afirmaram tê-lo feito, enquanto, em termos de inovações de processo, $11,7 \%$ das microempresas e $28,6 \%$ das pequenas afirmaram tê-las introduzido. 
As microempresas destacam-se no quesito "inovação no desenho dos produtos", uma vez que $85,7 \%$ delas afirmaram terem inovado, enquanto o desempenho das pequenas empresas é de $71,4 \%$, inferior aos $85,7 \%$ que essas mesmas firmas obtiveram no quesito "inovação de produto para a própria empresa".

No aspecto da gestão, observa-se que as microempresas, como regra, não introduziram inovações, embora $35 \%$ delas tenham adotado mudanças na estrutura organizacional. Entre as pequenas empresas, observa-se uma proporção muito mais significativa. Nelas, percebe-se a adoção de inovações na gestão $(42,8 \%)$ e na estrutura organizacional $(71,4 \%)$.

O impacto das inovações de produto sobre o faturamento das empresas mostrou-se significativo para a maior parte delas, pois metade afirmou que entre $16 \%$ e $75 \%$ de seu faturamento provinham dos novos produtos, enquanto para um percentual de 35\% o impacto foi desprezível, alcançando, no máximo, $5 \%$ de seu faturamento. As melhorias em produtos já existentes (inovações no desenho), ao contrário das inovações de produto, não resultaram em impacto perceptível para $62,5 \%$ das empresas, não tendo superado o nível de $5 \%$ do faturamento corrente. Para um pequeno grupo, representando $37,5 \%$ das empresas, o impacto sobre o faturamento situou-se entre $16 \%$ e $75 \%$.

Aproximadamente metade das empresas (43\%) avaliaram como de alta importância a introdução de inovações para a "melhoria da produtividade", "ampliação da diversidade de produtos" e "melhoria da qualidade dos produtos". Contrariamente, igual percentual das empresas consideradas na amostra não reconheceu essa importância, atribuindo a estes itens, o critério de avaliação: "nula importância".

O impacto das inovações sobre os custos não foi significativo, uma vez que as empresas não perceberam redução nos custos de energia e trabalho, o que indica um melhor efeito na redução dos custos de insumo, considerando que 52,4\% das empresas afirmaram ter obtido economias nesse item. Aspectos ambientais e normas de regulação não apresentaram efeitos significativos nas escolhas ou no desempenho das empresas.

Em termos do impacto das inovações sobre o mercado, as empresas avaliaram que as inovações foram mais importantes para preservar sua partici- 
pação nos mercados existentes do que para abrir novos, principalmente o externo. Avaliaram também, em uma posição intermediária, a importância das inovações para expandir o mercado interno. ${ }^{16}$

\section{COOPERAÇÃO COMO ESTRATÉGIA INOVATIVA NO APL}

Verificou-se que apenas 33\% das empresas da amostra realizaram atividade cooperativa entre 2000 e 2002, sendo menos freqüente entre as microempresas. Por gênero, os números são semelhantes: $27 \%$ das EAM afirmaram ter desenvolvido atividades cooperativas, contra $40 \%$ de respostas positivas das EAH. Verificando-se os dados, conclui-se que cerca de 70\% das empresas que desenvolveram atividade cooperativa ou são micro-EAH $(42,8 \%)$ ou pequenas EAM (28,5\%). Cruzando-se os dados referentes à cooperação com os que informam a atividade inovativa, e recortando a amostra em dois grupos, os "cooperativos" e aqueles "não cooperativos", percebe-se que o primeiro grupo apresenta um desempenho inovativo superior ao do segundo grupo. No grupo "cooperativo", 71,4\% introduziram "produto novo para a própria empresa", contra 64\% do grupo "não cooperativo", e, com maior ênfase, verifica-se que a introdução de "novos produtos no mercado nacional" foi realizada por $28,5 \%$ dos "cooperativos" contra $14,2 \%$ dos "não-cooperativos" (gráfico 2).

Gráfico 2: Desempenho inovativo relativo entre cooperativos e não-cooperativos

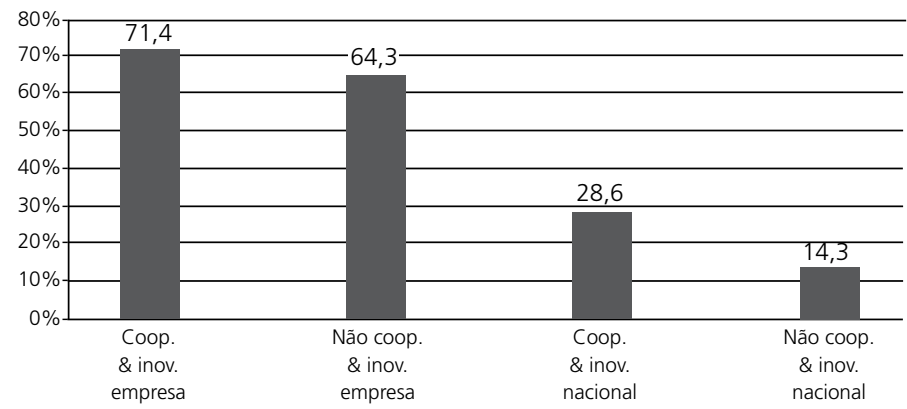

Grupos de empresas 
Gráfico 3: Barras dos APLS no fator relacionado à aprendizagem externa com agentes produtivos/demais agentes (fator 1)

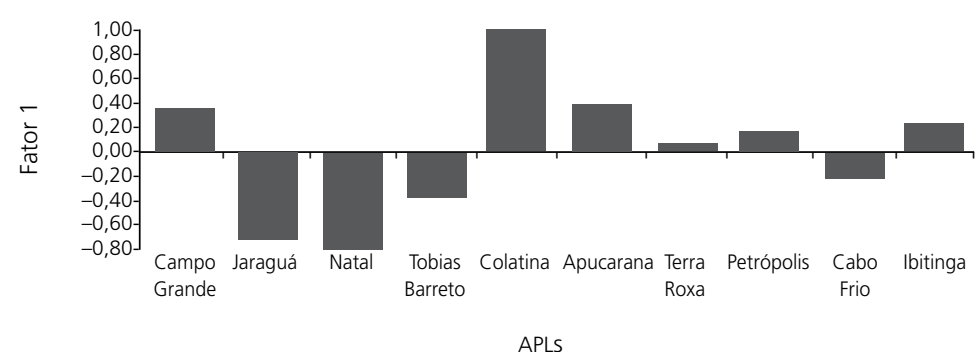

APLS

Gráfico 4: Barras dos APLs no fator relacionado

à aprendizagem com agentes de C\&T (fator 5)

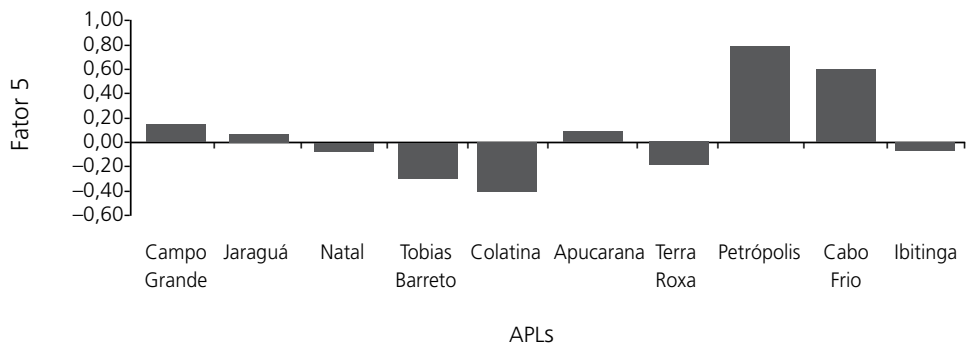

Fonte: Pesquisa de campo. Elaboração própria com base no software Statistica 6.0.

Gráfico 5: Barras dos APLs no fator relacionado às inovações incrementais (fator 4 )

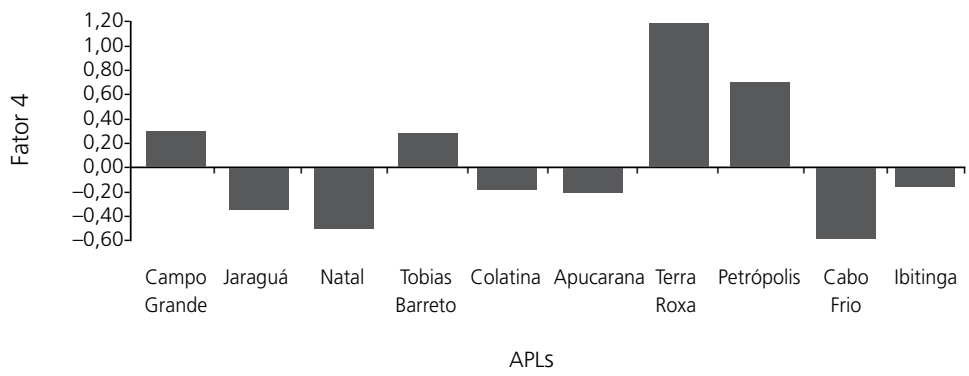

Fonte: Pesquisa de campo. Elaboração própria com base no software Statistica 6.0. 
Comparando-se esses resultados com outros estudos de APLs confeccionistas no Brasil (Cassiolato et al., 2006), verifica-se que Campina Grande destaca-se no uso de fontes externas de aprendizado com outros agentes (produtivos ou não) e com instituições de C\&T em particular (o que pode representar uma proxy para o papel do aprendizado cooperativo).

Se, em termos absolutos, a atividade confeccionista em Campina Grande não apresenta números destacados (inclusive pelo caráter tradicional da indústria sob análise), relativamente a outras aglomerações similares, seu desempenho inovativo situa-se entre os de maior destaque.

Os dados parecem indicar o acerto na ênfase conferida pela abordagem de Sistemas e Arranjos Produtivos e Inovativos Locais (Sapil) à importância da cooperação entre agentes econômicos, em decorrência da natureza tácita do conhecimento tecnológico e do caráter sistêmico do processo inovativo, pois, para a amostra pesquisada, a atividade cooperativa parece estar positivamente relacionada à capacidade de introduzir inovações de produto e, em particular, potencializa a capacidade de introduzir inovações relevantes para o mercado nacional, que exigem maior esforço tecnológico.

Verificando-se o grau de escolaridade entre as empresas que compõem os grupos "cooperativos" e "não-cooperativos", percebe-se que 100\% dos empresários do primeiro grupo possuíam nível superior (completo ou incompleto) à época de fundação da empresa, enquanto apenas 50\% dos empresários do segundo grupo encontravam-se nesse nível de escolaridade. Talvez por possuir maior acesso à informação, em especial pelo aprendizado acadêmico sobre o papel da cooperação e a importância da inovação nas sociedades modernas, os dados permitem concluir que a elevada escolaridade empresarial é fator importante na valorização das atividades cooperativa e inovativa, e, em especial, na atividade de P\&D.

As formas de cooperação avaliadas com "alta importância" pelas empresas foram "Desenvolvimento de Novos Produtos e Processos", "Design e Estilo de Produtos" e "Reivindicações", com 57,1\%, 57,1\% e 71,4\%, respectivamente. As formas de cooperação creditadas com os mais elevados percentuais de "nula importância" foram "Obtenção de Financiamento", com 100\% das respostas, e "Venda Conjunta de Produtos", “Compra de Insumos e Equipamentos" e "Outras", todas com o mesmo percentual de 71,4\%. 
Entre as empresas que realizaram atividades cooperativas, verifica-se que a avaliação da importância dos resultados da cooperação é variável de acordo com a forma específica em que esta foi realizada. Destacam-se como de "alta importância” as "Novas Oportunidades de Negócios" e o "Desenvolvimento de Novos Produtos", com 85,7\% e 75,4\%, respectivamente, ambas formas de cooperação associadas à introdução de novos produtos, guardando coerência com os resultados inovativos do grupo "cooperativo" de empresas, analisado anteriormente. Entre as formas de cooperação avaliadas como de "nula importância", destacam-se "Maior Inserção no Mercado Externo", "Melhoria nas Condições de Fornecimento dos Produtos" e "Introdução de Inovações Organizacionais”, com percentuais de 85,7\%, 71,4\% e $57,1 \%$, respectivamente.

\section{COOPERAÇÃO E ESTRATÉGIA INOVATIVA: O CONSÓRCIO dO ALGODÃo COLORIDO}

Os empresários ressaltaram, durante as entrevistas, a importância da associação de empresas diante da retração econômica do final dos anos 1990 (chamada de "crise do $2^{\circ}$ mandato FHC"), quando as MPEs enfrentavam dificuldades para permanecer no mercado.

Foi nesse cenário que um grupo de 10 empresas, percebendo que isoladamente suas chances de sobrevivência eram diminutas, estabeleceu uma estratégia cooperativa: a criação de um consórcio. Os objetivos iniciais seriam pecuniários e financeiros:

(i) Obter ganhos pecuniários de escala na compra coletiva de matériaprima a preços mais vantajosos.

(ii) Facilitar a obtenção de financiamentos em instituições bancárias, tendo como avalistas empresas do próprio consórcio, superando, assim, a barreira da inadimplência individual no Serasa.

O sucesso inicial dessa estratégia consolidou a conviç̧ão de que a cooperação entre MPEs constituía-se em um mecanismo valioso de fortalecimento empresarial, a despeito de possíveis perdas individuais. $\mathrm{O}$ estabelecimento de vínculos pessoais, o desenvolvimento da confiança mútua, os ganhos da difusão de informações intraconsórcio, contribuindo para eli- 
minação de ineficências e para maior homogeneização das capacidades tecnológicas, foram alguns resultados positivos da experiência consorciada. Essa confiança na força da cooperação foi fundamental para que os integrantes do consórcio vislumbrassem uma "janela de oportunidade" na pesquisa tecnológica desenvolvida pela Empresa Brasileira de Pesquisa Agronômica - Embrapa-algodão, localizada em Campina Grande.

O material existente no banco de germoplasma da Embrapa-algodão foi objeto de melhoramento genético, tendo como meta elevar a resistência e a uniformidade das fibras e estabilizar a sua coloração, especificamente nas fibras creme e marrom, além de aumentar sua produtividade. O produto obtido, o algodão colorido BRS 200-Marrom, possui características de resistência testadas na forma de fios, tecidos de malha e camisetas.

As malhas e os testes industriais foram processados no Centro de Tecnologia Têxtil do Senai, ${ }^{17}$ localizado no próprio município, tendo sido realizados ensaios de solidez da cor, encolhimento das malhas e resistência do tecido ao Pilling, comprovando-se a adequação às exigências de resistência às altas velocidades do processo de fiação da indústria têxtil.

A pesquisa que a Embrapa desenvolve com o algodão colorido abrange também uma variedade verde que já passou pelos testes de avaliação agrícola, tendo atingido o desempenho necessário à aprovação nos testes industriais. Superadas satisfatoriamente as etapas de testes industriais, a trajetória tecnológica a seguir está na busca de redução na perda de coloração do tecido, o que dificultava sua posterior comercialização. A pesquisa do algodão colorido ampliou-se para incluir o cruzamento dos algodões creme, marrom e verde, visando à obtenção de novas cores.

Surge, então, o Natural Fashion, tendo o algodão colorido como matériaprima-chave. ${ }^{18} \mathrm{O}$ desafio a ser enfrentado, entretanto, era considerável: desenvolver toda a cadeia produtiva do algodão colorido, a começar pelo soerguimento da cotonicultura estadual.

Conhecedores do processo produtivo de confecções, com um histórico local de larga experiência na cotonicultura e sediando a instituição de pesquisa que desenvolveu as novas variedades de algodão colorido naturalmente, estavam criadas as bases para que o consórcio de empresas evoluísse para uma estratégia competitiva mais ousada. Essa "ousadia” materializou- 


\section{Esquema 1: Cadeia produtiva e instituições de apoio ao consórcio do algodão colorido}

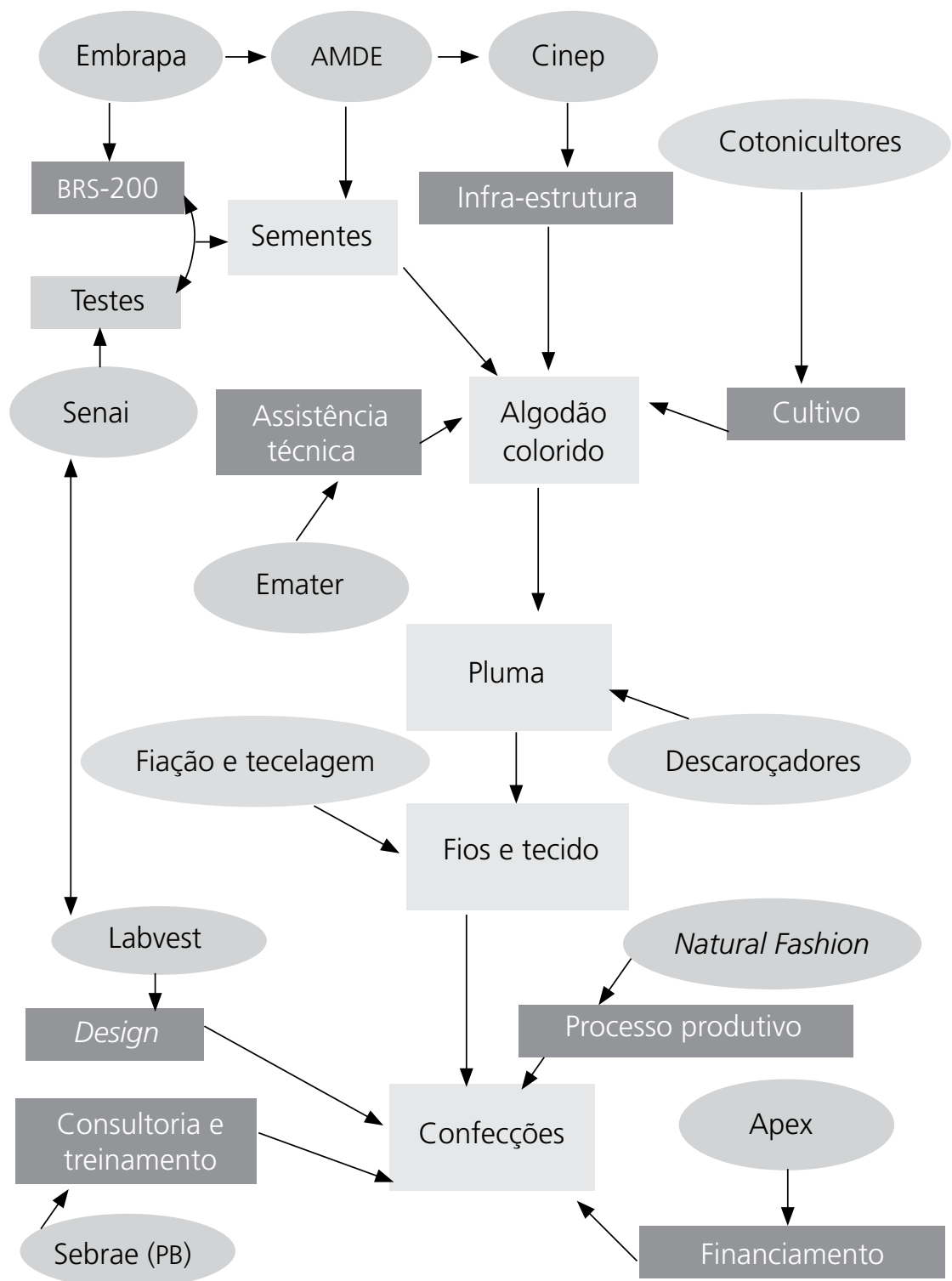


se com a criação de um consórcio de exportação de confecções em torno da fabricação e comercialização de peças de vestuários, acessórios e decoração, tendo o conceito de produto natural como diferencial competitivo.

A Paraíba viveu um período áureo na produção de algodão no século XIX (chamado de "ouro branco"), evento que inclusive está na origem do APL de calçados no Município de Campina Grande,${ }^{19}$ mas perdeu competitividade na cotonicultura nacional em face dos maiores níveis de produtividade no Centro-Oeste e em Estados como Bahia e Maranhão. Entretanto, o solo paraibano apresenta-se mais propício à variedade do algodão colorido que o dos demais Estados brasileiros. ${ }^{20}$ Tendo desenvolvido variedades vegetais adequadas ao uso industrial, a próxima barreira estava no estímulo à produção agrícola.

Com relação à principal matéria-prima, o algodão colorido, inicialmente a Agência Municipal de Desenvolvimento - $\mathrm{AMDE}^{21}$ contribuiu com suporte material, adquirindo sementes do algodão colorido e articulando agentes locais e na esfera estadual para viabilizar a distribuição das sementes para outras localidades. Dessa forma, a área plantada foi expandida de aproximadamente 600 ha de algodão colorido para 6.000 ha em 2003, ${ }^{22}$ ainda com dimensões reduzidas, mas suficientes para o início das operações fabris do consórcio. O esquema 1 anterior ilustra os elos da cadeia do algodão colorido.

A partir de articulações políticas, o governo do Estado mobilizou seus órgãos no sentido de apoiar o aumento da produção e da produtividade. O Governo paraibano atua através da Cinep, financiando a infra-estrutura da Secretaria de Agricultura, incentivando a cultura do algodão colorido, enquanto o governo federal apóia através da Emater, prestando assistência aos plantadores de algodão, e da Embrapa-algodão, desenvolvendo as variedades do algodão colorido em seu laboratório de Campina Grande.

A fiação e a tecelagem foram as etapas seguintes no desenvolvimento da cadeia produtiva do algodão colorido. Uma parceira importante para o início da fiação desse algodão foi a empresa Embratex, ${ }^{23}$ a maior unidade têxtil da América Latina, instalada em Campina Grande no início da década de 1990, através de incentivos do Finor/Sudene e do governo estadual. $^{24}$ 
À época, 2003, o algodão era plantado no Estado, descaroçado no Município de Patos, sertão paraibano, trazido para Campina Grande, onde era fiado, e, em seguida, enviado para Sergipe, onde era tecido pela empresa Ematesa. A presença de um agente externo ao APL, responsável pela fase de tecelagem do fio de algodão colorido, reduziu os ganhos de cooperação e aprendizado local, além de servir como canal de difusão de conhecimento e informações sobre a estratégia que se estabeleceu no APL a partir do algodão colorido.

Do ponto de vista de articulação política, apoio e liderança das empresas, o consórcio sempre esteve bem credenciado. Apesar de pequenas, as principais empresas envolvidas são líderes locais e, em particular, a sócia de uma delas acumulava a coordenação do consórcio com a presidência do Sindicato da Indústria de Confecções e Vestuário do Estado da Paraíba, ligado à Fiep, e a direção da Agência Municipal de Desenvolvimento - AMDE.

A articulação entre grupos econômicos e instituições relevantes para o APL de confecções foi formalizada através da criação do Instituto Casaco de Couro (ICC), composto pelo Sindvest, Senai, BNB, Embrapa, Sebrae, governo do Estado, principais agentes do APL. O ICC tem sede na Fiep desde abril de 2002, possui estatuto próprio e o objetivo de desenvolver a cadeia produtiva do algodão colorido para viabilizar o Natural Fashion.

O consórcio Natural Fashion mantém convênio com o sistema Fiep/Senai, havendo um grupo de pesquisa voltado para os objetivos do consórcio. O Sebrae e o Senai, através do Centro Tecnológico do Couro e do Calçado - CTCC, têm atuado, com o Labvest, no apoio ao setor de confecções do Estado através da prestação de serviços na área de desenho industrial (especializado em moda). ${ }^{25} \mathrm{O}$ trabalho do Labvest abrange aspectos ligados a design, modelagem, produção e qualidade, concentrando-se em produtos do algodão colorido, como roupas, acessórios e decoração. No entanto, embora tenha como principal foco o consórcio do algodão colorido, o Labvest também presta serviços aos demais produtores do APL.

Vale destacar que o trabalho atual do consórcio do algodão colorido também resgata o artesanato de Campina Grande, a partir da criação de um projeto com a participação da Prefeitura da Cidade, através da AMDE e das secretarias municipais, pelo qual as cooperativas e associações realizam trei- 
namento para aperfeiçoamento do trabalho artesanal, resultando no cadastramento de 53 "clubes de mães" em Campina Grande, especializados em bordados. As peças são adornadas com produtos do artesanato têxtil nordestino, para superar a monotonia da cor marrom, única disponível inicialmente. Essa estratégia permanece mesmo após a introdução de novas variedades de cores.

A Secretaria da Indústria e Comércio de Campina Grande, em parceria com a Embrapa e Senai/Labvest, incentivou a formação do consórcio, que contou também com o apoio financeiro da Apex (órgão do governo federal que apóia os consórcios para exportação), ${ }^{26}$ para estimular o desenvolvimento do produto, a criação e a promoção das coleções no exterior.

No primeiro ano de sua fundação, em 2000, o consórcio demonstrou grande impulso, pois o algodão colorido e antialérgico, cultivado no próprio Estado, tornou-se notícia no País inteiro. Um grande esforço de desenvolvimento do consórcio foi realizado: contratação de consultores-técnicos externos especializados, participação em feiras internacionais (Holanda), aperfeiçoamento de tecidos e realização de novas parcerias.

O sucesso tecnológico da Embrapa, entretanto, indica que o consórcio paraibano não deve considerar essa barreira à entrada no mercado suficiente para lhe conferir vantagens competitivas duradouras. O timing para obter as vantagens do "primeiro a se mover" pode ser bastante reduzido em face da velocidade da difusão tecnológica e dos progressos na adaptação da cultura a diferentes condições climáticas.

Adicionalmente, apesar do esforço coletivo, as empresas do Natural Fashion, com foco na exportação, ainda enfrentam dificuldades relacionadas à escala produtiva e ao controle de qualidade nos poucos lotes já exportados, o que tem constituído grande barreira ao desempenho nesse mercado, até o momento.

Passar a atuar na exportação para atendimento do exigente mercado europeu será, sem dúvida, um grande salto qualitativo para as empresas participantes do consórcio. O APL de confecções necessita vencer as barreiras impostas pelas grandes exigências dos mercados externos em termos da qualidade e quantidade do produto a ser exportado.

A exigência de alta qualidade nos produtos requer grau elevado de especialização e qualificação, processo que demandará o nivelamento tecnológi- 
co entre as empresas consorciadas, através de consultores e técnicos especializados. O Labvest capacita as empresas, treina seu pessoal e desenvolve coleções para as demais empresas do APL, além do consórcio Natural Fashion, porém enfrenta resistências tanto de parte dos empresários, que vêem riscos na atividade cooperativa, quanto da mão-de-obra, pois costureiras com longa experiência na atividade não absorvem com facilidade alterações nos procedimentos e técnicas que resultaram de vários anos de aprendizado e de construção de habilidades. A alternativa seria a contratação de outros profissionais especializados, de forma a minimizar o receio de quebra de segredo industrial.

O consórcio possuía capacidade para produzir no máximo 30 mil peças/ mês, enquanto os pedidos de clientes dos Estados Unidos alcançavam aproximadamente um milhão de peças (camisetas, em geral), o que inviabilizava as exportações. No entanto, a insuficiente escala produtiva, questão-chave para o sucesso comercial, poderia ser gradativamente superada à medida que novas empresas do APL fossem agregadas ao consórcio Natural Fashion e, simultaneamente, houvesse um esforço sistemático de capacitação tecnológica.

Os principais agentes empresariais ${ }^{27}$ pressionam pela implantação de um pólo industrial têxtil-confecções, localizado em área de antigos galpões desapropriados pelo governo municipal. O financiamento do pólo deverá ser promovido pelo governo do Estado, através da Cinep, Sebrae, governo federal e prefeitura municipal de Campina Grande. O projeto deveria ser implantado até o final de 2003, mas se encontrava paralisado na Cinep devido a problemas cadastrais de parte das empresas ${ }^{28}$ a serem beneficiadas.

A despeito da insuficiência de informações econômico-financeiras, parece claro que a probabilidade de sucesso do consórcio está fortemente condicionada à sua capacidade de aproveitar, no timing exigido, o conhecimento que está gerando acerca do algodão colorido, e de se estabelecer como referência na produção de roupas, acessórios e decorações desenvolvidas a partir deste. O pequeno porte das empresas envolvidas e a pouca experiência com o mercado internacional também têm constituído uma limitação relevante. Contudo, não se descarta a hipótese de que, em uma fase posterior, quando houver suficiente matéria-prima, o consórcio admita parceiros de maior porte. 


\section{CONCLUSÕES}

Os resultados da pesquisa empírica evidenciaram que há uma associação entre a ocorrência de cooperação (interempresarial ou interinstitucional, forma ou informalmente) e a elevação de indicadores inovativos, tais como valorização, freqüência e desempenho da atividade de busca de novas tecnologias (de produto ou processo, gestão ou organização).

A análise cuidadosa da base de dados permitiu concluir que o APL de confecções em Campina Grande representa, simultaneamente, um exemplo de sucesso e de fracasso na elaboração e execução de uma estratégia competitiva baseada na cooperação para inovação.

De um lado, obteve sucesso em formar um "cinturão institucional" no entorno do consórcio de MPEs, que, de forma articulada e com um claro objetivo comum, desenvolvem uma estratégia inovativa que exige a articulação de toda a cadeia produtiva do algodão colorido naturalmente.

De outro lado, fracassa duplamente:

(a) Ao não incorporar as demais empresas de confecções do município a essa mesma estratégia competitiva, comprometendo a eficácia do próprio consórcio (pela insuficiente escala produtiva) e a sobrevivência de todo o APL, o qual enfrentou uma trajetória descendente na última década.

(b) Ao não garantir a continuidade das políticas, programas e prioridades no fomento ao APL, em decorrência das disputas políticas e do forte "bairrismo" que caracteriza a rivalidade entre os Municípios de Campina Grande e João Pessoa.

A eficiência e o bem-estar coletivos podem se formar espontaneamente; todavia, o mecanismo pode ser muito lento e desperdiçar recursos. Usar algumas políticas para estimulá-los poderia trazer bons resultados. Uma primeira etapa, visando ao fortalecimento dos elos de cooperação social, empresarial e institucional, deve se apoiar no objetivo de fortalecer a dinâmica inovativa das empresas do APL através da implementação de dois vetores de políticas: (i) o incremento da formalização e territorialização dos processos de aprendizado e (ii) a ampliação do conjunto de empresas consorciadas e a "institucionalização" dos programas e ações em prol da estratégia de "cooperação para inovação", de forma a reduzir as incertezas quanto à sua continuidade diante da saudável alternância de poder. 


\section{NOTAS}

1. Algumas características das interações no âmbito das estruturas produtivas e institucionais estão indicadas em Campos \& Vargas (2003).

2. Desenvolvido pela RedeSist (ver www.redesist.ie.ufrj.br).

3. Realizada pelos autores em dois momentos, em 2003 e em 2005.

4. No final dos anos 1980, além da Paraíba apenas a Bahia e o Ceará haviam elaborado programas de incentivos.

5. A inadimplência dos empresários do setor tem sido generalizada, o que gera forte resistência dos agentes financeiros em conceder novos financiamentos.

6. As formas de interação ocorrem de variados modos e intensidades: às vezes esporádicas, outras recorrentes, em alguns casos formalizadas e em outros por relações informais.

7. Oscips são pessoas jurídicas de direito privado, recebendo recursos públicos e administrando sua utilização, em parceria com o Poder Público, para finalidades sociais, não possuindo fins lucrativos.

8. O cadastro da FIEP de 1992 registrou apenas as empresas de confecções de Campina Grande, o que não permitiu estimar a participação relativa desse Município no total do setor no Estado da Paraíba.

9. Deve-se ponderar que o cadastro da FIEP não é atualizado com a mesma presteza de seu registro formal, o que tende a "inflá-lo" no intervalo entre suas atualizações.

10. Mas tal hipótese é válida apenas no momento da fundação, uma vez que os questionários avaliaram quantos sócios havia na fundação da empresa, não quantos sócios a empresa possui atualmente.

11. Essa explicação necessitaria ser confrontada e/ou complementada, por uma análise da hipótese de shake-out, ou seja, a hipótese de que a quantidade de empresas em um "novo" segmento industrial, após exibir um período de expansão inicial, experimentaria uma fase de crescente concorrência, que se encarregaria de eliminar progressivamente as empresas que não se mostrarem competitivas.

12. Sebrae (PE), 2003.

13. Para a coleta de informações sobre a introdução de inovações, esta pesquisa utilizou o questionário formulado pela RedeSist, o qual segue as definições da Pintec. Nele, diferenciam-se as inovações (inovações de processos, inovações de produtos novos e inovações organizacionais) para as empresas daquelas referentes ao mercado ou ao setor nos quais as empresas atuam. Questões e especificidades locais exigiram pequenas adaptações no questionário, sem comprometimento da comparabilidade dos resultados em face de outros estudos também baseados na Pintec.

14. A maior incidência entre as microempresas, de um lado, deixa margem a dúvidas quanto ao adequado entendimento da atividade de $\mathrm{P} \& \mathrm{D}$ por parte dos microempresários entrevistados, mas, de outro lado, resulta da definição "ampla", adotada no questionário, para essa atividade. 
15. É o caso do consórcio do algodão colorido, tema da próxima seção.

16. A rigor, tem-se registro da exportação de três pequenos lotes de confecções, que representaram não mais do que uma tentativa de aprendizado e teste do mercado externo, sem significativo impacto comercial.

17. Trata-se do Laboratório do Vestuário (Labvest).

18. Entre as empresas fundadoras do consórcio, permanecem em atividade: Mix, Terral, Trapo, Cosmo e Ramil.

19. Pois a expansão da cotonicultura estimulou o crescimento populacional, gerando demanda para a pecuária de corte, enquanto as sobras do algodão alimentavam o gado.

20. De acordo com entrevistas com técnicos e consultores locais.

21. Empresa pública, vinculada à Prefeitura, coordena, programa e executa o desenvolvimento econômico e social do município (www.pmcg.pb.gov.br/amde).

22. Essa era a meta em 2003.

23. Empresa Brasileira de Fiação e Tecidos Ltda. É controlada pelo Grupo Coteminas. Para essa unidade industrial de larga escala, representou um elevado custo de set-up interromper seu processo fabril com o algodão branco, limpar todas as máquinas durante dois dias, fiar o algodão colorido por algumas horas, e novamente realizar a limpeza cuidadosa das máquinas para que não restasse um único fio de algodão colorido capaz de "contaminar" sua produção.

24. Vale salientar que a contaminação do algodão branco pelo algodão colorido é um obstáculo à difusão da cultura deste último, pois desde o plantio até as etapas de armazenamento e beneficiamento pode ocorrer o barramento, ou seja, a mistura entre as variedades genéticas (no cultivo) ou entre os fios, bastando um fiapo de algodão colorido para determinar a perda comercial do tecido branco (e vice-versa).

25. De fato, uma das dificuldades no trabalho do Labvest está na carência de pessoal qualificado, pois há apenas um profissional formado em desenho industrial.

26. Através de financiamento de um milhão de reais, dividido em várias parcelas.

27. A coordenadora do ICC acumulava, em 2004, as funções de coordenadora de Desenvolvimento Local da Secretaria de Desenvolvimento Econômico e de presidente do Sindvest.

28. Do total de 18 empresas que deverão fazer parte desse pólo, mais da metade encontra-se nessa situação, segundo entrevista realizada com agente local do Sebrae - Campina Grande.

\section{REFERÊNCIAS BIBLIOGRÁFICAS}

ALBUQUERQUE, E. M. Notas sobre os determinantes tecnológicos do catching-up: uma introdução à discussão sobre o papel dos sistemas nacionais de inovação na periferia. Revista Estudos Econômicos, São Paulo, IPE, v. 27, n. 2, p. 220-253, 1997. 
BECATTINI, G. The Marshallian Industrial District as a Socio-Economic Notion. In: PYKE, F.; BACATTINI, G.; SENGENBERGER, W. (Eds.). Industrial districts and inter-firm cooperation in Italy. Geneva: International Institute for Labour Studies-ILO, 1990, p. 37-51.

BRASIL. Ministério do Trabalho. Relação Anual de Informações Sociais/Rais. Brasília, 2001.

BRESCHI, S.; MALERBA, F. Sectoral innovation systems: technological regimes, Schumpeterian dynamics, and spatial boundaries. In: EDQUIST C. (Org.). Systems of innovation: technologies, institutions and organizations. Londres: Pinter, 1997.

CAMPOS, R. R.; VARGAS, M. Forms of governance, learning mechanisms and localized innovation: a comparative analysis in local productive systems in Brazil. In: THE FIRST Globelics Conference. Innovation Systems and Development Strategies for the Third Millennium. Disponível em: <http://redesist.ie.ufrj.br/dados/nt_count. php. Acesso em: 20 dez. 2005. Rio de Janeiro, 2003.

CASSIOLATO et al. Processos de aprendizagem e inovação em setores tradicionais: os arranjos produtivos locais de confecções no Brasil. In: Anais do XXIV Encontro Nacional da ANPEC, 2006.

CARLSSON, B. et al. A. Innovation systems: analytical and methodological issues. Research Policy, Elsevier, v. 31, n. 2, p. 233-245, fev. 2002.

CAVALCANTI FILHO, P. F.; MOUTINHO, L. M. G. Arranjo produtivo de micro e pequenas empresas de confecções em Campina Grande. Arranjos produtivos locais: uma nova estratégia de ação para o Sebrae. RedeSist/IE/UFRJ, 2004. Disponível em: <http://www.ie.ufrj.br/redesist.

EDQUIST, C. (Ed.). Systems of Innovation: technologies, institutions, and organizations. Londres: Pinter Publishers, 1997.

FREEMAN, C. Technology policy and economic performance: lessons from Japan. Londres: Pinter Publishers, 1987.

JOHNSON, B.; LUNDVALL, B. A. Promovendo sistemas de inovação como resposta à economia do aprendizado crescentemente globalizada. In: LASTRES, H. M. M.; CASSIOLATO, J. E. ARROIO, A. (Orgs.). Conhecimento, sistemas de inovação e desenvolvimento. Rio de Janeiro: UFRJ, Contraponto, 2005.

LASTRES, H. M. M.; CASSIOLATO, J. E.; ARROIO, A. Sistemas de inovação e desenvolvimento: mitos e realidade da economia do conhecimento global. In: LASTRES, H. M. M.; CASSIOLATO, J. E. Arroio, A. (Orgs.). Conhecimento, sistemas de inovação e desenvolvimento. Rio de Janeiro: UFRJ, Contraponto, 2005.

LUNDVALL, B. A. (Ed.). National Innovation Systems: towards a theory of innovation and interactive learning. Londres: Pinter Publishers, 1992.

NELSON, R. R. (Ed.). National Innovation Systems: a comparative analysis. Nova York-Oxford: Oxford University Press, 1993.

SAXENIAN, A. Regional Advantage: culture and competition in Silicon Valley and Route 128. Cambridge (Mass.): Harvard University Press, 1994. 
SCHMITZ, H. Collective efficiency: growth path for small-scale industry. Journal of Development Studies, Inglaterra, v. 31, n. 4, abr., 1995.

SEBRAE-PE. Projeto de confecções do Agreste de Pernambuco. Recife, 2003.

SINDICATO da Indústria do Vestuário no Estado da Paraíba/Sindvest Relação dos Associados. (mimeo), 2002.

STORPER, M. The regional world. Territorial development in a global economy. Londres: The Guilford Press, 1997. 
